\title{
Measuring shear strength parameters of polymer-added bentonite-sand mixtures in laboratory experiments
}

\author{
Hakki O. Ozhan ${ }^{1, *}$ \\ ${ }^{1}$ Altinbas University, Civil Engineering Department, Bagcilar-Istanbul, Turkey
}

\begin{abstract}
In order to evaluate the shear strength parameters of an anionic polymer-added bentonite-sand mixture that was permeated with tap water, Proctor compaction tests and direct shear tests were performed on the mixture with a bentonite content of $15 \%$ by mass. The polymer content in the polymer-bentonite mixture was chosen as $0.5,1,2,5,10,15$ and $20 \%$ by mass, respectively. According to the results, maximum dry unit weight $(\mathrm{\gamma dmax})$ first decreased as the polymer content was increased to $1 \%$ and then, increased. $\mathrm{ydmax}$ of $20 \%$ polymer-added mixture and the mixture without polymer addition was measured as 17.55 and $17.28 \mathrm{kN} / \mathrm{m}^{3}$, respectively. Test results indicated that cohesion (c) increased and internal friction angle (ø) decreased due to polymer addition. $2 \%$ polymer addition caused an increase of $42 \mathrm{kPa}$ in c but a decrease of $4.2^{\circ}$ in $\varnothing$. As the polymer content increased, maximum shear strength of the mixture $\left(\tau_{\max }\right)$ increased. $\tau_{\max }$ increased from 171.8 to $197.8 \mathrm{kPa}$ as the polymer content was increased from 0 to $2 \%$. As a result, $2 \%$ anionic polymer-added bentonite-sand mixture provided sufficient increase in the shear strength of the mixture.
\end{abstract}

\section{Introduction}

Bentonite-sand mixtures are preferred to be used as barriers in waste containment areas by minimizing leachate advection through the ground soil layers. Hydraulic conductivity, shear strength and compressibility are the most significant properties of bentonite-sand mixtures which are taken into account for the design of the barrier of the waste containment areas [1]. The bentonite component of the mixtures provides very low permeability whereas the sand component generally maintains high shear strength [2]. Adding various types of polymers to bentonite-sand mixtures is a treatment method that might cause an increase in both mechanical and hydraulic performance of these mixtures. [1] conducted direct shear and unconfined compression tests on bentonite-river sand mixtures with 5,10 and $20 \%$ bentonite content by mass, respectively. The results of these tests showed that the unconfined compressive strength, the cohesion and the Young's modulus all increased with an increase in the bentonite content, while the angle of internal friction decreased. [3] performed direct shear tests on silt-sand mixtures with silt contents ranging from 10 to $70 \%$ by mass. According to the test results, cohesion increased from 3.8 to $20.1 \mathrm{kPa}$ and internal friction angle decreased from 46.1 to $36.1^{\circ}$ as the silt content increased from 0 to $35 \%$ which resulted in a decrease in the shear strength. Contrarily, cohesion decreased and internal friction angle increased for the mixtures with a silt content of 50 and $70 \%$. They also added a copolymer (poly methyl methacrylate) with a content of $0.025,0.05$ and $0.1 \%$ by mass to the mixtures, respectively and the results showed that cohesion increased and internal friction angle decreased as the polymer content increased. [4] conducted direct shear tests on polyurethane organic polymer-polypropylene fiber-sand mixtures. As a result, both the polymer and the fiber improved the shear strength of the sand. The soil that had the highest shear strength was the mixture with $4 \%$ polymer and $0.2 \%$ fiber content. Cohesion and internal friction angle of this mixture was measured as $80.4 \mathrm{kPa}$ and $27.9^{\circ}$, respectively. Polymer treatment also resulted in an increase in the shear strength of a sandy soil [5]. An elastic copolymer with a content of $0.5,1$ and $1.5 \%$ by mass was added to the sand, respectively. According to the direct shear test results, both cohesion and internal friction angle increased due to polymer addition. The sand had a cohesion of zero and an internal friction angle of $50^{\circ}$ whereas the cohesion and internal friction angle of $1.5 \%$ polymer-treated sand were measured as $313 \mathrm{kPa}$ and $84^{\circ}$, respectively [5]. On the other hand, standard Proctor compaction tests were conducted on the same sand treated with the same polymer and a polymertreated low plastic clay. Test results indicated that the maximum dry unit weight decreased, then increased and finally decreased again due to $0.5,1$ and $1.5 \%$ polymer addition, respectively for both the sand and the clay [5]. In another study, an increase in polymer content resulted in higher mechanical properties for polypropylene polymer-bentonite mixtures [6]. [7] performed unconfined compression tests on biopolymer-sand mixtures. Test results showed that polymer addition up

\footnotetext{
Corresponding author: hakki.ozhan@altinbas.edu.tr
} 
to $4 \%$ by mass caused almost 2 times increase in the shear strength of the untreated sand.

The objective of this research was to investigate the effects of polymer addition on the shear strength parameters of a bentonite-sand mixture with a bentonite content of $15 \%$ by mass. The polymer was chosen as an anionic polymer that was especially used for improving the hydraulic performance of soils by lowering the permeability. However, shear strength parameters of the bentonite-sand mixture treated with this polymer had to be determined in order to decide whether the polymer would improve the resistance against probable high hydraulic loads that might exist due to the collection of leachates over the mixtures or angular solid wastes that might damage the mixtures. For this reason, direct shear tests [8] and standard Proctor compaction tests [9] were performed on the polymer-treated mixtures. The polymer content in the polymer-bentonite mixtures was chosen as $0.5,1,2,5,10,15$ and $20 \%$ by mass, respectively. By performing the direct shear tests, cohesion $\left(\mathrm{kN} / \mathrm{m}^{2}\right)$, internal friction angle $\left({ }^{\circ}\right)$ and maximum shear strength $\left(\mathrm{kN} / \mathrm{m}^{2}\right)$ were measured whereas maximum dry unit weight $\left(\mathrm{kN} / \mathrm{m}^{3}\right)$ with respect to optimum water content (\%) was obtained by conducting the standard Proctor compaction tests.

\section{Materials}

The sand used in the bentonite-sand mixtures was chosen as a poor-graded sand (SP) and $100 \%$ of its particles passed through \#4 sieve (4.75 mm opening size) whereas $61.6 \%$ and $0.2 \%$ of its particles passed through \#20 (0.85 $\mathrm{mm}$ opening size) and \#200 sieve (0.074 mm opening size), respectively [10].

The bentonite in the mixtures was a granular, sodium bentonite with a liquid limit and plasticity index of $640 \%$ and $612 \%$, respectively [11]. Mass/unit area of the bentonite was $4800 \mathrm{~g} / \mathrm{m}^{2}$ [12], while it had a specific gravity of 2.69 [13].

The powdered polymer that was added to the bentonite-sand mixtures consisted of copolymers of acrylamide $\left(\mathrm{C}_{3} \mathrm{H}_{5} \mathrm{NO}\right)$ that were negatively charged and was composed of approximately 9 times more soluble anions than cations in terms of mass [14].

\section{Testing Methods}

Direct shear and standard Proctor compaction tests were conducted on the bentonite-sand mixtures that were treated with different amounts of the anionic polymer. First, a polymer content of $0.5,1,2,5,10,15$ and $20 \%$ by mass was mixed with the oven-dried bentonite, respectively by using a spatula. Afterwards, the polymerbentonite mixtures were taken into polyethylene cups and aged for 24 hours which resulted in homogeneous mixtures [15]. Then, the mixtures were mixed with the oven-dried sand in order to obtain the bentonite-sand mixtures with a bentonite content of $15 \%$ by mass. The bentonite content was chosen as $15 \%$ because this amount maintained the optimum permeability for a bentonite-sand mixture [16].
For the compaction tests, the bentonite-sand mixtures were compacted in a steel mold that had a diameter and a volume of $101.6 \mathrm{~mm}$ and $944 \mathrm{~cm}^{3}$, respectively. The mixtures were compacted in three equal layers by a hammer that had a mass of $2.5 \mathrm{~kg}$. The hammer was dropped from a height of $30.5 \mathrm{~mm}$ and each layer was compacted with 25 blows [9]. The content of the tap water that was added to the mixture was increased in each test in order to obtain the maximum dry unit weight $\left(\gamma_{d m a x}\right)$. However, the dry unit weight began to decrease as the water content was increased after obtaining $y_{\text {dmax }}$. For each test, the measured dry unit weight was plotted against the corresponding water content as shown in Fig. 1. According to Fig. 1, the peak dry unit weight was expressed as the maximum dry unit weight $\left(\mathrm{y}_{\mathrm{dmax}}\right)$ and this value was obtained at the optimum water content ( $\left.\mathrm{w}_{\mathrm{opt}}\right)$.

For the direct shear tests, the bentonite-sand mixtures that were compacted at the optimum water content were placed in a shear box with a cross-section of $10 \mathrm{~cm} \mathrm{x} 10$ $\mathrm{cm}$. The height of the box was $1.5 \mathrm{~cm}$. Tap water was placed in the shear box and drainage was maintained through the porous plates at the bottom and top of the mixture in the shear box. First, primary consolidation was completed by applying the normal load on the mixture; then, every mixture was sheared at three specific normal stress values. The applied normal stress $(\sigma)$ was taken as 50,100 and $200 \mathrm{kPa}$, respectively. Under all of these normal stresses, the mixtures were sheared until failure occurred. Shear was applied by moving the upper part of the shear box relative to the lower part in order to cause failure of the bentonite-sand mixture. The rate of shearing was chosen slow enough $(0.2 \mathrm{~mm} / \mathrm{s})$ to provide drainage. Failure was reached under consolidated-drained conditions by dissipating the excess pore water pressures [8]. However, there are some limitations of this test. Failure of the soil does not occur along the weakest plane; it occurs along a predetermined horizontal plane. Furthermore, it is not possible to measure the exact value of the pore water pressure during a direct shear test. For this reason, total stress analysis can not be made correctly. Although sufficient time was given to obtain full drainage and zero pore water pressure, there is no control for the drainage of the soil in a direct shear test. The maximum shear stress at which the failure of the mixtures occurred was defined as the peak shear stress $\left(\tau_{\mathrm{p}}\right) . \tau_{\mathrm{p}}$ was calculated by dividing the measured peak shear force $\left(T_{p}\right)$ by the crosssectional area (A) of the bentonite-sand mixture in the shear box.

For each mixture, three peak shear stress values were plotted against the corresponding three normal stress values $(50,100$ and $200 \mathrm{kPa})$ as shown in Fig. 3. The ordinate of the line that passed through these three points was the cohesion (c) whereas the slope of the line was the internal friction angle $(\varnothing)$ of the mixture. Finally, maximum shear strength $\left(\tau_{\max }\right)$ of the mixtures was calculated. 


\section{Test Results and Discussion}

After the termination of the compaction tests, $\mathrm{ydmax}$ and $\mathrm{w}_{\mathrm{opt}}$ of $5 \%$ polymer-added bentonite-sand mixture were measured as $17.17 \mathrm{kN} / \mathrm{m}^{3}$ and $13.5 \%$, respectively as shown in Fig. 1. Similar results were obtained from the other compaction tests that were conducted on the polymer-added mixtures. $y_{d}$ reached a peak value due to water addition and then, began to decrease as the water content increased as can be seen in Fig. 1. Ydmax and $\mathrm{w}_{\mathrm{opt}}$ values that were measured in these tests are listed in Table 1.

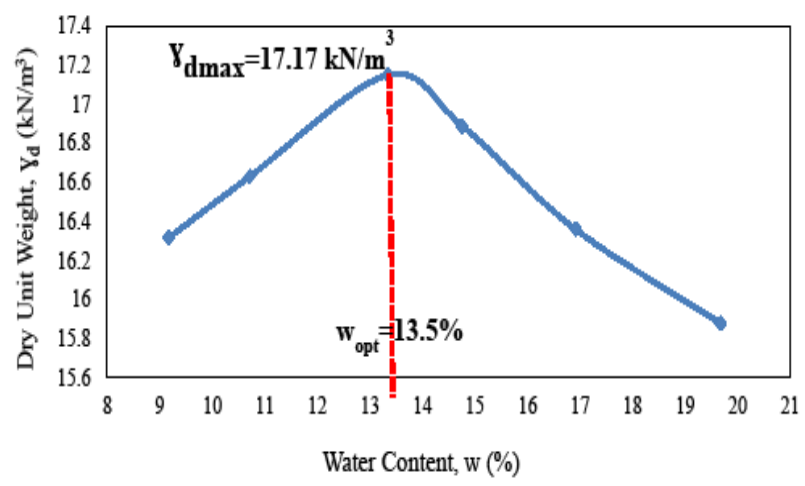

Fig. 1. Compaction curve for $5 \%$ polymer-added bentonitesand mixture

Table 1. Standard Proctor compaction and direct shear test results

\begin{tabular}{cccccccc}
\hline \multicolumn{7}{c}{ SAND+15\% BENTONITE } \\
\hline $\begin{array}{c}\text { Poly } \\
\text { mer } \\
(\%)\end{array}$ & $\begin{array}{c}\mathrm{Jd}_{\mathrm{d}} \\
\left(\mathrm{kN} / \mathrm{m}^{3}\right)\end{array}$ & $\begin{array}{c}\mathrm{W}_{\text {opt }} \\
(\%)\end{array}$ & $\begin{array}{c}\mathrm{c} \\
(\mathrm{kPa})\end{array}$ & $\varnothing\left(^{\circ}\right)$ & $\begin{array}{c}\tau_{\max } \\
(\mathrm{kPa}) \\
(\sigma=200 \\
\mathrm{kPa})\end{array}$ & $\begin{array}{c}\tau_{\max } \\
(\mathrm{kPa}) \\
(\sigma=100 \\
\mathrm{kPa})\end{array}$ & $\begin{array}{c}\tau_{\max } \\
(\mathrm{kPa}) \\
(\sigma=50 \\
\mathrm{kPa})\end{array}$ \\
\hline 0 & 17.28 & 13.4 & 73 & 29.2 & 171.8 & 122.4 & 97.7 \\
0.5 & 17.06 & 13.7 & 82 & 27.3 & 173.4 & 127.7 & 104.9 \\
1 & 16.88 & 14 & 95 & 26.2 & 182.3 & 138.7 & 116.8 \\
2 & 17.11 & 13.8 & 115 & 25 & 197.8 & 156.4 & 135.7 \\
5 & 17.17 & 13.5 & 138 & 23.8 & 216.5 & 177.2 & 157.6 \\
10 & 17.35 & 13.3 & 147 & 23.3 & 223.7 & 185.3 & 166.2 \\
15 & 17.42 & 13.2 & 156 & 23.1 & 231.9 & 194 & 175 \\
20 & 17.55 & 13.1 & 164 & 23.1 & 239.9 & 202 & 183 \\
\hline
\end{tabular}

As the polymer content was increased up to $1 \%, \mathrm{ydmax}$ decreased; however, further increase in the polymer content resulted in an increase in $\mathrm{Jdmax}_{\mathrm{mas}}$ as shown in Fig. 2 . The bentonite-sand mixture without polymer addition had a $\gamma_{\text {dmax }}$ value of $17.28 \mathrm{kN} / \mathrm{m}^{3}$ whereas $\gamma_{\mathrm{dmax}}$ of 1 and $20 \%$ polymer-added mixtures was measured as 16.88 and $17.55 \mathrm{kN} / \mathrm{m}^{3}$, respectively. The decrease in $\mathrm{ydmax}$ could be attributed to a decrease in the density of the bentonite-sand mixture as the polymer was added to the mixture up to a content of $1 \%$ by mass. On the other hand, more polymer treatment might have decreased the capillary tension of the mixture that resulted in a denser and more stable structure. This could be the reason for the increase in $\gamma_{d \max }$ [5]. According to these results, although $\gamma_{d \max }$ initially decreased and then, increased due to polymer addition, the amount of change in Ydmax could be considered to be insignificant.

After the termination of the direct shear tests, $\mathrm{c}$ and $\varnothing$ of $5 \%$ polymer-added bentonite-sand mixture were measured as $138 \mathrm{kPa}$ and $23.8^{\circ}$, respectively as can be seen in Fig. 3.

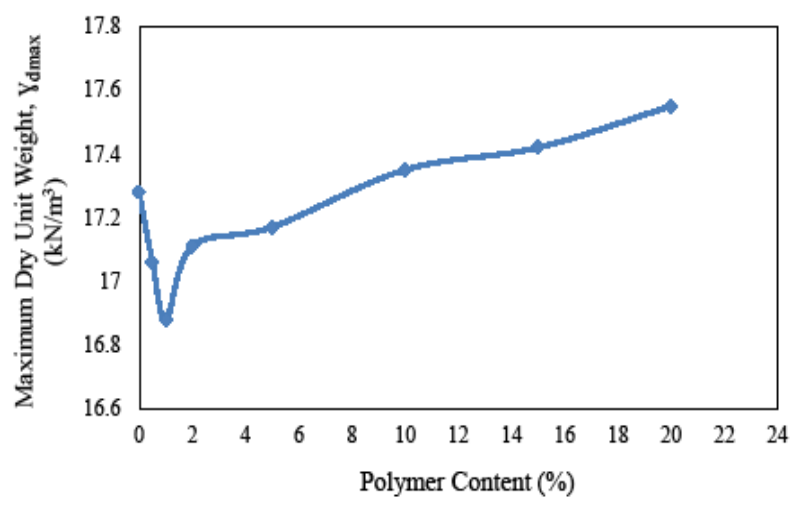

Fig. 2. Maximum dry unit weight ( $\mathrm{\gamma dmax}$ ) change due to polymer addition

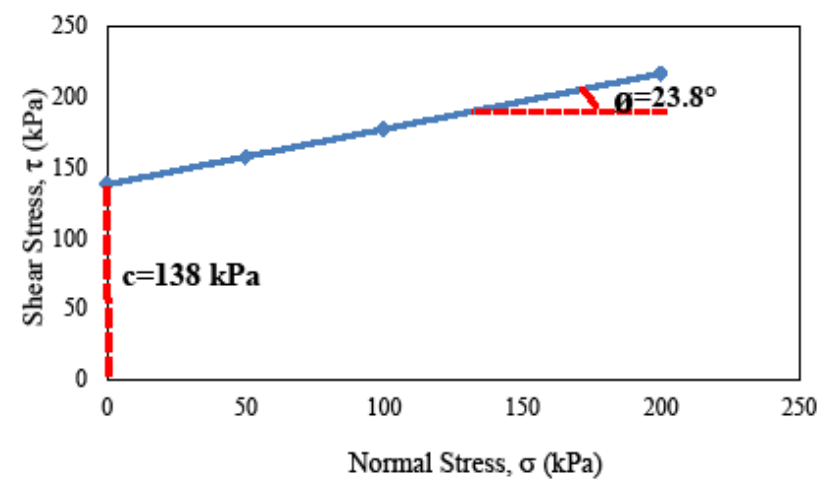

Fig. 3. Direct shear test result for $5 \%$ polymer-added bentonitesand mixture

As shown in Figs. 4 and 5, c increased and ø decreased nonlinearly as the polymer content increased. The amount of increase in $\mathrm{c}$ and decrease in $\varnothing$ were measured higher up to a polymer content of $2 \%$. As listed in Table 1, c of the bentonite-sand mixture without polymer addition was $73 \mathrm{kPa}$ whereas 2 and $20 \%$ polymer-added mixtures had a cohesion value of 115 and $164 \mathrm{kPa}$, respectively. On the other hand, $\varnothing$ of the bentonite-sand mixture without polymer addition, 2 and $20 \%$ polymer-added mixtures was measured as $29.2,25$ and $23.1^{\circ}$, respectively. As shown in Fig. $6, \tau_{\max }$ change with the change of polymer content was similar with that of cohesion change. $\tau_{\max }$ increased nonlinearly as the polymer content was increased. The amount of increase in $\tau_{\max }$ was higher when the polymer content was increased from 0 to $2 \%$ at all the tested normal stress $(\sigma)$ values $(50,100$ and $200 \mathrm{kPa}) . \tau_{\max }$ of the bentonite-sand mixture without polymer addition, 2 and $20 \%$ polymeradded mixtures was measured as 171.8, 197.8 and 239.9 $\mathrm{kPa}$, respectively at a normal stress of $200 \mathrm{kPa}$. 


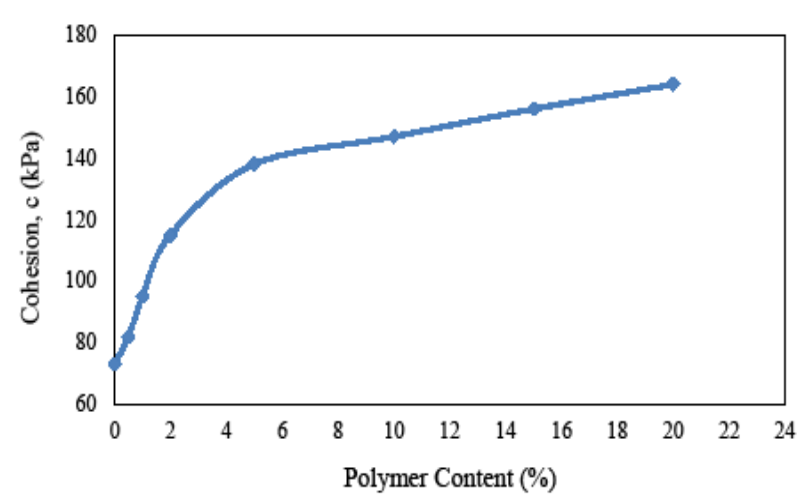

Fig. 4. Peak cohesion (c) change due to polymer addition

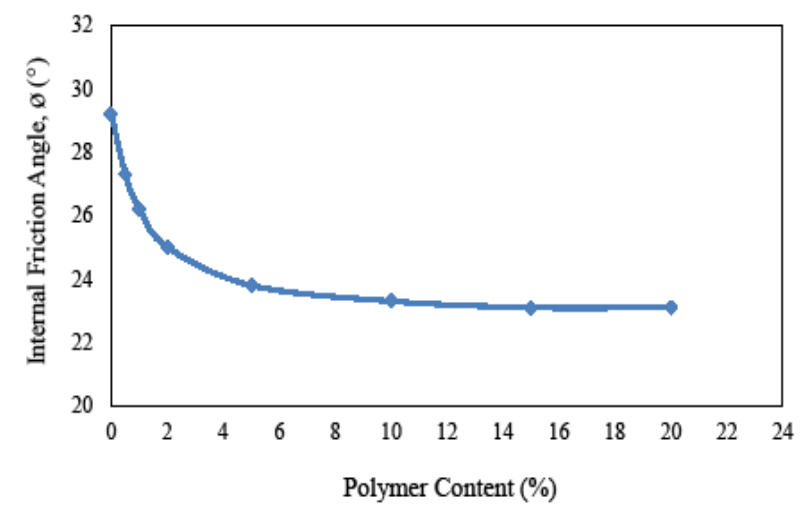

Fig. 5. Peak internal friction angle (ø) change due to polymer addition

The mixture of the polymer and water had the capability to enwrap the bentonite-sand particles and could result in a more compact structure. As the polymer content increased, the polymer amount mixed with water also increased and this mixture blocked the voids among the bentonite-sand particles [4]. This interlocking effect that could cause stronger bonding in the structure might be the main reason for the increase in the shear strength of the bentonite-sand mixture due to polymer addition. Polymer treatment resulted in reduction of voids among the soil particles. As the voids were closed, more compact and stable structure was obtained and the shear strength of the soil increased. However, after reaching a peak polymer content value ( $2 \%)$, almost all of the voids were considered to be closed. More increase in the polymer content leaded to only a slight increase in shear strength as can be seen in Fig. 6. On the other hand, the increase in the cohesion due to the polymer treatment could be attributed to the stronger interaction between the polymer and the bentonite-sand particles when compared with the interaction of the bentonite-sand mixtures [17]. However, the decrease in the internal frictional angle occurred due to a possible formation of smoother surfaces of the sand particles as the polymer was added to the mixture [4].

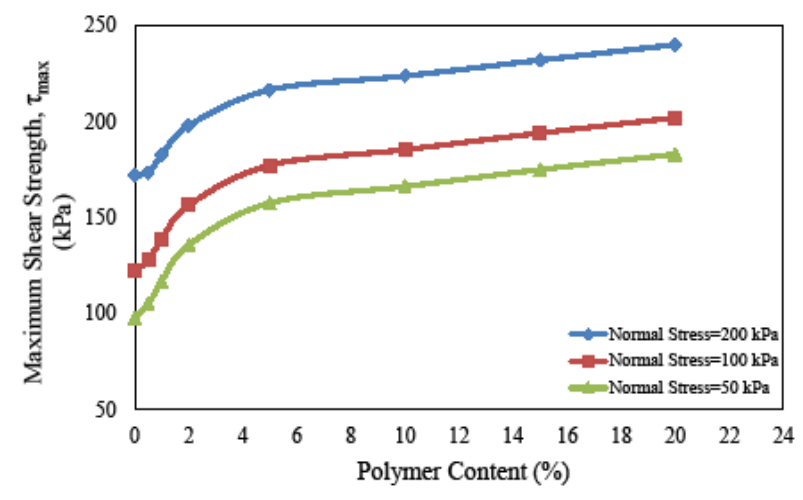

Fig. 6. Maximum shear strength $\left(\tau_{\max }\right)$ change due to polymer addition

\section{Conclusions}

The powdered anionic polymer that was added to a granular, sodium bentonite-poor graded sand mixture with a bentonite content of $15 \%$ by mass, resulted in an increase in the cohesion (c) and a decrease in the internal friction angle (ø).

As the polymer content was increased to $2 \%$, cohesion increased by $42 \mathrm{kPa}$ and internal friction angle decreased by $4.2^{\circ}$. Although additional increase in the polymer content caused an increase in the cohesion and a decrease in the internal friction angle, these changes were not as drastically as those obtained with the polymer content of up to $2 \%$. As a result, $20 \%$ polymeradded mixture had a cohesion and internal friction angle of $164 \mathrm{kPa}$ and $23.1^{\circ}$, respectively.

Maximum shear strength $\left(\tau_{\max }\right)$ of the mixture increased due to the polymer addition. Reduction of the voids among the soil particles occurred as the polymer content was increased. This reduction caused the shear strength of the soil mixture to increase. The amount of increase was found to be higher for the mixture with a polymer content of up to $2 \%$. Maximum shear strength of $2 \%$ polymer-added mixture was measured as 197.8 $\mathrm{kPa}$ whereas the mixture without polymer addition had a maximum shear strength of $171.8 \mathrm{kPa}$ at a normal stress $(\sigma)$ of $200 \mathrm{kPa}$.

Polymer addition resulted in a slight increase in the maximum dry unit weight $\left(\mathrm{\gamma dmax}_{\mathrm{d}}\right.$ ) of the mixture although $\gamma_{d m a x}$ decreased as the polymer content increased up to $1 \%$. $20 \%$ polymer-added mixture and the mixture without polymer addition had a $\mathrm{ydmax}$ of 17.55 and 17.28 $\mathrm{kN} / \mathrm{m}^{3}$, respectively.

In conclusion, an adequate amount of increase in the shear strength of the bentonite-sand mixture was obtained when the anionic polymer content was increased to $2 \%$ by mass.

In addition to the high performance of the anionic polymer as a hydraulic barrier, the increase in the shear strength of a bentonite-sand mixture due to the addition of the same polymer can improve the resistance against probable high hydraulic loads that might exist due to the collection of leachates over the mixtures or angular solid wastes that might damage the mixtures. 


\section{References}

1. A.F. Ghazi, Ms. Thesis (Edith Cowan University, Perth, Australia, 2015)

2. G. Sallfors, A.L. Oberg-Hogsta, Geotech. Geol. Eng., 20, 1, 65-80 (2002)

3. S.A. Naeini, A. Mahdavi, E. J. Geotech. Eng., 14, A (2009)

4. J. Liu, Q. Feng, Y. Wang, Y. Bai, J. Wei, Z. Song, Advances in Materials Sci. and Eng., $10.1155 / 2017 / 2370763$ (2017)

5. G.E. Welling, Ms. Thesis (Polytechnic State University, California, USA, 2012)

6. M. Sarkar, K. Dana, S. Ghatak, A. Banerjee, Bulletin of Materials Science, 31, 1, 23-28 (2008)

7. L. Guo, Ms. Thesis (Iowa State University, Ames, Iowa, USA, 2014)

8. ASTM D3080, Standard Test Method for Direct Shear Test of Soils Under Consolidated Drained Conditions (ASTM International, West Conshohocken, PA, USA, 2011)

9. ASTM D698, Standard Test Methods for Laboratory Compaction Characteristics of Soil Using Standard Effort (ASTM International, West Conshohocken, PA, USA, 2012)

10. ASTM D6913, Standard Test Methods for ParticleSize Distribution (Gradation) of Soils Using Sieve Analysis (ASTM International, West Conshohocken, PA, USA, 2017)

11. ASTM D4318, Standard Test Method for Liquid Limit, Plastic Limit and Plasticity Index of Soils (ASTM International, West Conshohocken, PA, USA, 2010)

12. ASTM D5993, Standard Test Method for Measuring Mass per Unit Area of Geosynthetic Clay Liners (ASTM International, West Conshohocken, PA, USA, 2014)

13. ASTM D854, Standard Test Methods for Specific Gravity of Soil Solids by Water Pycnometer (ASTM International, West Conshohocken, PA, USA, 2014)

14. SNF Floerger, Technical data sheet for anionic polymers (Kucukcekmece-Istanbul, Turkey, 2016)

15. A.R. Razakamanantsoa, G. Barast, I. Djeranmaigre, Appl. Clay Sci., 59-60, 103-114 (2012)

16. E. Guler, H.O. Ozhan, S. Karaoglu, Appl. Clay Sci., 157, 139-147 (2018)

17. N.S.L. Louzada, Ms Thesis (Pontificia Universidade Catolica do Rio de Janeiro, Rio de Janerio, Brazil, 2015) 